\title{
Determinan Persepsi Masyarakat terhadap Fungsi Gigi Tiruan di Wilayah Kerja Puskesmas Juai
}

\author{
M. Bahrul Ilmi ${ }^{1}$, Khairul Anam ${ }^{2}$, Erwin Ernadi ${ }^{3}$ \\ ${ }^{1,2,3}$ Program Studi S1 Kesmas UNISKA MAB Banjarmasin \\ Email: illmy1202@gmail.com
}

Submitted : 31/05/2021

Accepted: 10/09/2021

Published: 15/09/2021

\begin{abstract}
Dentures have many functions, of course all of these things are to improve the degree of health, but there are many factors that cause people to refuse to use dentures. In the district. Juai still has very few health workers (dentists) so that people are more directing themselves to dental artisans who are identical to dentures. The purpose of this study was to determine the determinants of public perceptions of denture function. This study used an analytic survey method with a cross sectional approach. The sample here is accidental sampling, namely the people in the working area of Puskesmas Juai. The instrument used in this study was a questionnaire / interview sheet containing a list of questions about denture function and a questionnaire regarding public perceptions. The data were then processed and analyzed using the chi square statistical test to test the research hypothesis. The results showed that there was no relationship between denture function variables and other variables such as attention, interest, experience \& memory, uniqueness \& contrast of dentures. The chance of respondents knowing the function of dentures is 4 times higher for respondents with high attention category, 3 times higher for respondents with interest category, 3 times higher for respondents with remembering category \& 1.5 times higher for respondents with unique category. It is advisable to provide information about the benefits, stages of manufacture \& other denture functions. As a learning medium, denture information should be improved from both electronic media and family support, especially related health workers such as dentists, dental nurses \& dental technicians to maximize their knowledge on the function of dentures in health promotion such as outreach to the public \& making electronic media.
\end{abstract}

Keywords: attention, dentures, experiences \& memories, interests, perception, uniqueness \&contrasts.

Abstrak
Gigi tiruan mempunyai banyak fungsinya yang pastinya semua hal tersebut untuk meningkatkan derajat kesehatan, tetapi banyak faktor yang menyebabkan masyarakat tidak mau menggunakan gigi tiruan. Di Kec. Juai masih sangat minim tenaga kesehatan (dokter gigi) sehingga masyarakat lebih mengarahkan diri untuk ke tukang gigi yang identik dengan gigi tiruan. Tujuan penelitian ini untuk mengetahui determinan persepsi masyarakat terhadap fungsi gigi tiruan. Penelitian ini menggunakan metode survey analitik dengan pendekatan cross sectional. Sampel disini adalah accidental sampling, yaitu masyarakat di wilayah kerja Puskesmas Juai. Instrumen yang digunakam dalam penelitian ini adalah berupa lembar petanyaan (kuesioner)/wawancara yang berisi daftar pertanyaan tentang fungsi gigi tiruan \& kuesioner mengenai persepsi masyarakat. Data kemudian diolah dan dianalisis dengan uji statistika chi square untuk menguji hipotesis penelitian. Hasil penelitian menunjukkan tidak ada hubungan antara variabel fungsi gigi tiruan dengan variabel lainnya seperti perhatian, minat, pengalaman \& ingatan, keunikan \& kekontrasan pada gigi tiruan. Peluang responden mengetahui fungsi gigi tiruan 4 kali lebih tinggi pada responden dengan kategori perhatian tinggi, 3 kali lebih tinggi pada responden dengan kategori berminat, 3 kali lebih tinggi pada responden dengan kategori mengingat \& 1.5 kali lebih tinggi pada responden dengan kategori unik. Disarankan perlu pemberian informasi mengenai manfaat, tahapan-tahapan pembuatan \& fungsi gigi tiruan yang lain. Sebagai media pembelajaran, informasi gigi tiruan lebih ditingkatkan baik dari media elektronik ataupun dukungan keluarga, khususnya tenaga kesehatan terkait seperti dokter gigi, perawat gigi \& teknisi gigi memaksimalkan keilmuannya mengenai 
fungsi gigi tiruan dalam melakukan promosi kesehatan seperti penyuluhan ke masyarakat \& pembuatan media-media elektronik

Kata Kunci : persepsi, gigi tiruan, perhatian, minat, pengalaman \& ingatan, keunikan \& kekontrasan.

\section{PENDAHULUAN}

Kesehatan gigi di Indonesia sebagai negara berkembang masih jauh dari kata memuaskan, dari data Riskesdas 2018, sebanyak $57.6 \%$ penduduk Indonesia menderita penyakit gigi dan mulut. Penyebab timbulnya penyakit gigi dan mulut ini mempunyai banyak faktor, diantaranya ialah pengetahuan masyarakat mengenai kesehatan gigi yang berhubungan dengan kebersihan gigi (oral hygiene) masih sangat rendah. (Infodatin, 2019).

Oleh karena itu jika menginginkan peningkatan derajat kesehatan gigi pada masyarakat maka haruslah bersedia dan mengubah pola pikir dari tidak tahu menjadi tahu mengenai kesehatan gigi. Dalam bidang kesehatan gigi, hal ini merupakan tugas utama dari pendidikan atau penyuluhan kesehatan.

$$
\text { Di tahun }
$$

menurutRisetKesehatanDasar(Riskesdas)

Departemen Kesehatan Republik Indonesia, melaporkan bahwa kehilangan gigi ditemukan pada kelompok umur 45-54 tahun sebesar 1,8\%,55-64 tahun sebesar $5,9 \%$, dan pada kelompok umur 65 tahun keatas, kehilangan gigi mencapai $17,6 \%$. Pemakaian gigi tiruan diperlukan apabila seseorang telah kehilangan giginya.

Berdasarkan Riskesdas tahun 2013, prevalensi 3 provinsi penduduk yang bermasalah gigi dan mulut terbanyak yaitu Sulawesi Selatan (10,3\%), Kalimantan Selatan (8\%) dan Sulawesi Tengah $(6,4 \%)$.

Dari data Riskesdas 2018, Kalimantan Selatan tidak lagi berada di urutan 5 besar Provinsi di Indonesia mengenai masalah kesehatan gigi dan mulut, tetapi hal tersebut belum bisa dibanggakan karena dilihat dari data Riskesdas 2013 \& 2018 hampir dua kali lipat peningkatan permasalahan kesehatan gigi dan mulut.
Di tahun 2014, untuk kabupaten Balangan sendiri hanya mempunyai total 4 orang dokter gigi yang tersebar masingmasing di Kec. Batu Mandi, Kec. Paringin, Kec. Paringin Selatan \& Kec. Halong. Sedangkan Kec. Juai yang merupakan Kecamatan terbesar kedua setelah Kec. Halong masih belum mempunyai dokter gigi, dan hal ini belum berubah sampai di tahun 2017.

Hampir seluruh wilayah Indonesia dengan mudah "tempat praktik" tukang gigi dengan ciri gambar gigi putih bergusi merah menyala dapat dijumpai. Beberapa tindakan praktik tukang gigi yang membahayakan masyarakat antara lain: pembuatan gigi tiruan tanpa mencabut sisa akar dan menambal gigi yang berlubang, pembuatan gigi tiruan langsung tanpa pencetakan, pembuatan gigi tiruan lepasan permanen, penambalan gigi tanpa pembuangan jaringan karies atau perawatan saluran akar, serta pemasangan alat orthodontik cekat dengan tujuan untuk variasi (Usri, 2007).

Walaupun dianggap membahayakan, masyarakat masih banyak memanfaatkan jasa tukang gigi yang dipengaruhi karakteristik masyarakat seperti variabel tingkat pengetahuan \& keyakinan dalam menggunakan gigi tiruan mempunyai hubungan yang bermakna, sedangkan variabel pendidikan, pekerjaan dan pendapatan tidak mempunyai hubungan yang bermakna (Silvia, 2014)

Pemakaian gigi tiruan berfungsi sebagai pengganti gigi yang hilang, pemelihara jaringan yang masih ada yaitu jaringan gigi, gusi dan tulang. Pemakai gigi tiruan harus betul-betul memperhatikan kebersihan gigi tiruan dan gigi aslinya, hanya saja sulit membersihkan gigi tiruan, sekalipun dengan sikat gigi. Akibatnya, dapat menyebabkan munculnya gangguan 
lain di mulut, seperti tumbuhnya mikroorganisme (jamur, bakteri dan kuman), ataupun lesi.

Selain adanya alasan menyebabkan gangguan lain di mulut, sikap dari orangorang yang sudah mempunyai dan menggunakan gigi tiruan pun masih mempunyai persentasi lebih kecil dibandingkan yang mendukung dikarenakan ketidaknyamanan saat awal menggunakannya, padahal sebelumnya ada ketertarikan saat melihat orang disekitarnya yang terlihat lebih awet muda \& giginya terlihat rapi. (Fauzan, 2017)

Persepsi masyarakat yang rendah berdasarkan penampilan, pengunyahan \& pengucapan juga mempunyai banyak faktor seperti keadaan sosial yang tidak terlalu memperdulikan kesehatan gigi, semakin bertambah usia menjadikan lebih sulit beradaptasi menggunakan gigi tiruan \& kurang tertarik pada estetika (Putranti, 2011).

Di Kecamatan Juai sendiri masih banyak giginya kurang terawat karena faktor eksternal dan internal seperti penggunaan air sungai untuk MCK dan senang makanan manis yang akhirnya menyebabkan rasa sakit, gangguan pengunyahan dan kesehatan lainnya (Ilmi, 2017).

Dari permasalahan ini, dapat dikatakan sangat minimnya tenaga kesehatan (dokter gigi) yang ada di Kabupaten Balangan khususnya di Kec. Juai \& observasi awal yang memperlihatkan banyaknya tukang gigi yang identiknya adalah pembuatan gigi tiruan,

Pemakaian gigi tiruan banyak mempunyai fungsi seperti pengganti gigi yang hilang, pemelihara jaringan gigi yang masih ada, estetika, dll. Hanya saja, banyak faktor yang menyebabkan masyarakat tidak mau menggunakan gigi tiruan seperti keadaan sosial, adaptasi dalm penggunaan $\&$ kurang tertarik dengan estetika.

\section{METODE PENELITIAN}

Penelitian dilakukan di Puskesmas Juai, Kec. Juai Kab. Balangan. Penelitian dilaksanakan pada bulan November 2020 sampai dengan bulan April 2021, menggunakan metode survey analitik dengan pendekatan cross sectional. Penelitian ini mencoba menggali tentang bagaimana dan mengapa fungsi gigi tiruan dapat meningkatkan persepsi masyarakat untuk derajat kesehatan serta mempelajari dinamika korelasi antara faktor risiko dan efek dengan melakukan sekali pengukuran pada waktu yang bersamaan.

Sampel disini adalah accidental sampling, yaitu masyarakat Puskesmas Juai dengan kriteria inklusi sampel Dapat berkomunikasi dengan baik,Berusia produktif, Bersedia menjadi responden. Variabel terikat disini adalah fungsi gigi tiruan, untuk variabel bebas yaitu persepsi masyarakat dilihat dari perhatian, minat, pengalaman \& ingatan, keunikan \& kekontrasan, terhadap fungsi gigi tiruan.

\section{HASIL DAN PEMBAHASAN}

Berdasarkan data pada tabel 1 mengenai Variabel fungsi gigi tiruan, diketahui sebagian besar di kategori belum mengetahui yaitu sebanyak 71 responden (94.7 \%). Untuk variabel perhatian pada gigi tiruan, diketahui sebagian besar berada di kategori tinggi yaitu sebanyak 35 responden $(46.7 \%)$. Pada variabel minat pada gigi tiruan, diketahui hampir seimbang pada kedua kategori yaitu 37 responden $(49.3 \%)$ berminat \& 38 responden $(50.7 \%)$ tidak berminat. Pada variabel pengalaman \& ingatan, diketahui sebagian besar di kategori tidak mengingat yaitu sebanyak (56 responden $(74.7 \%)$. Berdasarkan variabel keunikan \& kekontrasan,diketahui sebagian besar di kategori unik yaitu sebanyak 49 responden $(65 \%)$. 
Tabel 1. Distribusi frekuensi variabel fungsi gigi tiruan dan persepsi masyarakat dilihat dari perhatian, minat, pengalaman \& ingatan, keunikan \& kekontrasan

\begin{tabular}{lcc}
\hline \multicolumn{1}{c}{ Variabel } & n & \% \\
\hline Fungsi Gigi Tiruan & & \\
Mengetahui & 4 & 5,33 \\
Belum mengetahui & 71 & 94,7 \\
Perhatian & & \\
Tinggi & 30 & 40 \\
Sedang & 35 & 46,7 \\
Rendah & 10 & 13.3 \\
Minat & & \\
Berminat & 37 & 49,3 \\
Kurang berminat & 38 & 50,7 \\
Pengalaman \& ingatan & & \\
Mengingat & 19 & 25,3 \\
Tidak mengingat & 56 & 74,7 \\
Keunikan \& kekontrasan & & \\
Unik & 49 & 65,3 \\
Tidak Unik & 26 & 34,7 \\
\hline
\end{tabular}

Tabel 2. Hasil Analisis Bivariat

\begin{tabular}{|c|c|c|c|c|c|c|}
\hline \multirow{3}{*}{ Variabel } & \multicolumn{4}{|c|}{ Fungsi Gigi Tiruan } & \multirow{3}{*}{$P$ value } & \multirow{3}{*}{$\mathbf{O R}$} \\
\hline & \multicolumn{2}{|c|}{ Mengetahui } & \multicolumn{2}{|c|}{ Belum mengetahui } & & \\
\hline & $\mathbf{n}$ & $\%$ & $\mathbf{N}$ & $\%$ & & \\
\hline \multicolumn{7}{|l|}{ Perhatian } \\
\hline Tinggi & 3 & 4 & 27 & 36 & \multirow[t]{2}{*}{0.295} & \multirow[t]{2}{*}{4.889} \\
\hline Sedang \& rendah & 1 & 1.3 & 44 & 58.7 & & \\
\hline \multicolumn{7}{|l|}{ Minat } \\
\hline Berminat & 3 & 4 & 34 & 45.3 & \multirow[t]{2}{*}{0.358} & \multirow[t]{2}{*}{3.265} \\
\hline Tidak berminat & 1 & 1.3 & 37 & 49.3 & & \\
\hline \multicolumn{7}{|c|}{ Pengalaman \& ingatan } \\
\hline Mengingat & 2 & 2.7 & 17 & 22.7 & \multirow[t]{2}{*}{0.264} & \multirow[t]{2}{*}{3.176} \\
\hline Tidak mengingat & 2 & 2.7 & 54 & 72 & & \\
\hline \multicolumn{7}{|c|}{ Keunikan \& kekontrasan } \\
\hline Unik & 4 & 5.3 & 45 & 60 & \multirow[t]{2}{*}{0.291} & \multirow[t]{2}{*}{1.578} \\
\hline Tidak unik & 0 & 0 & 26 & 34.7 & & \\
\hline
\end{tabular}


Dilihat dari tabel 2, responden pada variabel perhatian yang perhatiannya sedang \& rendah sebanyak 45 orang, sebagian besar responden tersebut yang belum mengetahui fungsi gigi tiruan sebanyak 44 orang $(58.7 \%)$. Untuk responden dengan variabel minat, kedua kategori mempunyai nilai yang seimbang yaitu berminat-belum mengetahui fungsi gigi tiruan sebanyak 34 orang $(45.3 \%) \&$ tidak berminat-belum mengetahui fungsi gigi tiruan sebanyak 37 orang (49.3\%). Responden pada variabel pengalaman \& ingatandengan kategori tidak mengingat sebanyak 56 orang, sebagian besar responden tersebut yang belum mengetahui fungsi gigi tiruan sebanyak 54 orang (72 $\%)$. Responden pada variabel keunikan \& kekontrasan dengan kategori unik sebanyak 49 orang, sebagian besar responden tersebut yang belum mengetahui fungsi gigi tiruan sebanyak 45 orang $(60 \%)$.

\section{Pembahasan}

Sebagian besar responden termasuk dalam kategori belum mengetahui fungsi gigi tiruan yaitu sebanyak 71 orang $(94,7 \%)$. Banyaknya responden yang belum mengetahui fungsi gigi tiruan dikarenakan kurangnya informasi, sebagian besar responden hanya mengetahui fungsi gigi tiruan sebagai alat pengunyah, membantu dalam memperbaiki pengunyahan \& kesehatan gigi mulut. Fungsi yang lain dari penggunaan ggi tiruan yaitu stabilitas terhadap gigi yang lain, meningkatkan percaya diri, terlihat awet muda \& mencegah sakit kepala akibat gangguan otot rahang. Sejalan dengan penelitian Mamesah, dkk (2015), sebagian besar responden belum begitu paham bahwa pemakaian gigi tiruan, dapat mengembalikan bentuk wajah yang berubah menjadi normal akibat kehilangan gigi. Gangguan sendi rahang dapat dicegah dengan memakai gigi tiruan merupakan fungsi selanjutnya, individu yang mengalami gangguan sendi dan telah memakai gigi tiruan, perlahan gangguan pada TMJ akan hilang sehingga tidak akan lagi merasakan nyeri atau sakit. Selanjutnya, sebagian besar responden juga masih kurang yakin bahwa perubahan penampilan dapat diperbaiki dengan memakai gigi tiruan.

Hasil analisis bivariat dari variabel perhatian dengan variabel fungsi gigi tiruan, dilihat dari hasil uji statisticdiperoleh $p$-value $=0,295 \mathrm{serta}$ nilai Odds Ratio (OR) sebesar 4.889 (95\% $\mathrm{CI}=0.484-49.417)$. Dengan $p$-value $>0,05$, yang artinya tidak ada hubungan yang bermakna antara perhatian dengan fungsi gigi tiruan. Nilai Odds Ratio (OR) sebesar 4.889 menunjukkan bahwa responden kategori perhatian tinggi mempunyai peluang mengetahui fungsi gigi tiruan 4 kali lebih tinggi dibandingkan responden yang belum mengetahui fungsi gigi tiruan. Secara teori, dapat dikatakan bahwa antara perhatian dengan fungsi gigi tiruan tidak berhubungan ini didapatkan dari hasil penelitian yang menunjukkan gigi tiruan sebagai media pembelajaran lebih dominan tidak terlaksana dan responden belum mengetahui fungsi gigi tiruan. Hal ini dikarenakan responden kebanyakannya membuat gigi tiruan di tukang gigi \& tidak menjelaskan minimal secara teori mengenai fungsi gigi tiruan. Hal ini sesuai menurut Notoatmodjo (2011), kurangnya melibatkan pendidikan kesehatan dalam program-program pelayanan kesehatan memberikan pengaruh langsung terhadap pemilihan pelayanan kesehatan. Dalam hal ini responden lebih memilih jasa tukang gigi yang tentunya kurang dalam memberikan informasi mengenai fungsi gigi tiruan.

Hasil analisis bivariat dari variabel minat dengan variabel fungsi gigi tiruan, dilihat dari hasil uji statisticdiperoleh $p$ value $=0.358$ serta nilai Odds Ratio (OR)sebesar 3.265 (95\% CI $=0.324-$ 
32.909). Dengan p-value >0,05, yang artinya tidak ada hubungan yang bermakna antara minat dengan fungsi gigi tiruan. Nilai Odds Ratio (OR) sebesar 3,265 menunjukkan bahwa responden dengan kategori berminat mempunyai peluang mengetahui fungsi gigi tiruan 3 kali lebih tinggi dibandingkan responden yang belum mengetahui fungsi gigi tiruan. hasil penelitian menunjukkan responden lebih banyak tidak berminat untuk menyarankan keluarga ataupun orang terdekat untuk menggunakan gigi tiruan dikarenakan adanya rasa segan terkecuali ada yang bertanya mengenai fungsi gigi tiruan. Penelitian ini sejalan dengan Sinaga (2021) yang menyatakan minat dalam arti keinginan atau dorongan dalam diri seseorang menggunakan gigi tiruan pada masyarakat pra lansia sebanyak $47.5 \%$.

Hasil analisis bivariat dari variabel pengalaman \& ingatan dengan variabel fungsi gigi tiruan, dilihat dari hasil uji statisticdiperoleh $p$-value $=0.264$ serta nilai Odds Ratio (OR)sebesar 3.176 (95\% $\mathrm{CI}=0.415-24.291)$. Dengan $p$-value $>0,05$, yang artinya tidak ada hubungan yang bermakna antara pengalaman \& ingatan dengan fungsi gigi tiruan. Nilai Odds Ratio (OR) sebesar 3.176 menunjukkan bahwa responden kategori mengingat pengalaman \& ingatan mempunyai peluang mengetahui fungsi gigi tiruan 3 kali lebih tinggi dibandingkan responden yang belum mengetahui fungsi gigi tiruan. Secara teori, dapat dikatakan bahwa antara pengalaman \& ingatan dengan fungsi gigi tiruan tidak berhubungan didapatkan dari hasil penelitian yang menunjukkan responden lebih dominan belum pernah diberikan informasi mengenai manfaat \& fungsi gigi tiruan. Hal ini dikarenakan responden hanya mendapatkan informasi secara singkat di media elektronik, kurangnya dukungan dari keluarga \& sosial budaya serta. fungsi gigi tiruan hanya berdasarkan estetika agar tidak malu saat berbicara.
Menurut Yuvensius Pili (2020), dukungan keluarga dalam arti status perkawinan \& faktor budaya merupakan salahsatu alasan kurangnya perawatan kesehatan gigi mulut \& memeriksakan diri ke pelayanan kesehatan terkait.

Hasil analisis bivariat dari variabel keunikan \& kekontrasan dengan variabel fungsi gigi tiruan, dilihat dari hasil uji statisticdiperoleh $p$-value $=0,291$ serta nilai Odds Ratio (OR)sebesar 1.578 (95\% $\mathrm{CI}=0.484-49.417)$. Dengan p-value $>0,05$, yang artinya tidak ada hubungan yang bermakna antara keunikan \& kekontrasan dengan fungsi gigi tiruan. Nilai Odds Ratio (OR) sebesar 1.578 menunjukkan bahwa responden dengan kategori unik mempunyai peluang mengetahui fungsi gigi tiruan 1.5 kali lebih tinggi dibandingkan responden yang belum mengetahui fungsi gigi tiruan.Dapat dikatakan bahwa antara keunikan \& kekontrasan dengan fungsi gigi tiruan tidak berhubungan secara teori. Hal ini didapatkan dari hasil penelitian yang menunjukkan gigi tiruan dapat dibuat menyesuaikan ukuran \& warna dalam mulut lebih dominan tidak terlaksana, dikarenakan responden hanya memerlukan sebagai pengganti gigi yang diminta selesai dengan cepat. Keunikan \& kekontrasan gigi tiruan yang dapat dibuat menyesuaikan ukuran \& warna dalam mulut menjadikan terlihat menarik seperti gigi asli, tetapi hal tersebut terdiri dari beberapa tahapan. Dimulai dari rencana perawatan dengan segala aspek dan perawatan pendahuluan sebelum perawatan definitif yang tentunya secara keseluruhan perlu dikomunikasikan dengan pasien (Salim, 2017).

\section{SIMPULAN}

Berdasarkan hasil penelitian diketahui bahwa pada variabel fungsi gigi tiruan yang belum mengetahui sebanyak 71 responden $(94.7 \%)$. Variabel perhatian yang tinggi pada gigi tiruan sebanyak 35 responden 
(46.7\%). Variabel minat pada gigi tiruan hampir seimbang pada kedua kategori yaitu 37 responden $(49.3 \%)$ berminat \& 38 responden $(50.7 \%)$ tidak berminat.Variabel pengalaman $\&$ ingatan sebagian besar tidak mengingat yaitu sebanyak (56 responden $(74.7 \%)$. Variabel keunikan \& kekontrasan sebagian besar di kategori unik yaitu sebanyak 49 responden (65\%).

Tidak ada hubungan antara fungsi gigi tiruan dengan perhatian. Hasil uji Chi Square di peroleh $\mathrm{p}$-value $=0.295 \&$ OR 4.889 yang artinya peluang mengetahui fungsi gigi tiruan 4 kali lebih tinggi pada responden dengan kategori perhatian tinggi. Tidak ada hubungan antara fungsi gigi tiruan dengan minat. Hasil uji Chi Square di peroleh $\mathrm{p}$-value $=0.368 \&$ OR 3.265 yang artinya peluang mengetahui fungsi gigi tiruan 3 kali lebih tinggi pada responden dengan kategori berminat dengan gigi tiruan. Tidak ada hubungan antara fungsi gigi tiruan dengan pengalaman $\&$ ingatan. Hasil uji Chi Square di peroleh p-value = $0.264 \&$ OR 3.176 yang artinya peluang mengetahui fungsi gigi tiruan 3 kali lebih tinggi pada responden dengan kategori mengingat. Tidak ada hubungan antara fungsi gigi tiruan dengan keunikan \& kekontrasan. Hasil uji Chi Square di peroleh $\mathrm{p}$-value $=0.291 \&$ OR 1.578 yang artinya peluang mengetahui fungsi gigi tiruan 1.5 kali lebih tinggi pada responden dengan kategori unik.

\section{SARAN}

Perlunya peningkatan pemberian informasi mengenai manfaat, tahapantahapan pembuatan \& fungsi gigi tiruan yang lain seperti stabilitas terhadap gigi yang lain, meningkatkan percaya diri, terlihat awet muda \& mencegah sakit kepala akibat gangguan otot rahang. Gigi tiruan sebagai media pembelajaran lebih ditingkatkan baik dari media elektronik ataupun dukungan keluarga, agar dapat mengurangi rasa segan dalam mencari informasi yang khususnya mengenai tahapan-tahapan pembuatan gigi tiruan. Tenaga kesehatan terkait seperti dokter gigi, perawat gigi \& teknisi gigi memaksimalkan keilmuannya mengenai fungsi gigi tiruan dalam melakukan promosi kesehatan seperti penyuluhan ke masyarakat \& pembuatan media-media elektronik.

\section{DAFTAR PUSTAKA}

Dinkes Kab. Balangan (2017). Profil kesehatan Kabupaten Balangan Tahun 2017. Paringin, Kalimantan Selatan.

Fauzan, A., \& Ilmi, M. B. (2017). Hubungan Umur Dan Sikap Mengenai Gigi Tiruan Dengan Lama Penggunaan Gigi Tiruan Pada Pasien Di Klinik Gigi Ilham Banjarmasin 2016. Prosiding Hasil Penelitian Dosen-Dosen UNISKA 2017. Banjarmasin : LPPM UNISKA MAAB

Ilmi, M. B., \& Ernadi, E. (2018). Peningkatan Pengetahuan Cara Menggosok Gigi Dengan Kejadian Karies Gigi Melalui Upaya Penyuluhan (Edukasi) Kesehatan Pada Masyarakat Desa Juai Kecamatan Juai Kabupaten Balangan. Jurnal Pengabdian AlIkhlas Universitas Islam Kalimantan Muhammad Arsyad Al Banjary, Volume.2, Nomor.2, 1-5.

Kemenkes RI. (2019). Kesehatan Gigi Nasional.INFODATIN, Pusat Data dan Informasi Kemenkes RI. Jakarta : Kementerian Kesehatan RI.

Mamesah, M. M., Wowor, V. N., \& Siagian, K. V. (2015). Persepsi Masyarakat Kecamatan Tompaso Terhadap Pemakaian Gigi Tiruan. eGiGi, 3(2).

Notoatmodjo, S. (2011). Kesehatan Masyarakat Ilmu dan Seni.Jakarta : Rineka Cipta 
Pili, Y., Utami, P. A. S., \& Yanti, N. L. P. E. (2020). Faktor-faktor yang Berhubungan dengan Kebersihan Gigi dan Mulut pada Lansia. Jurnal Ners Widya Husada, 5(3), 95-104.

Putranti, D. T., \& Chandra, H. (2011).

Rendahnya persepsi masyarakat terhadap pemakaian gigi tiruan di Desa Ujung Rambung, Kecamatan Pantai Cermin, Kabupaten Serdang Bedagai. Dentofasial, Volume.10, Nomor.2, 79-131.

Riset Kesehatan Dasar (2007). Jakarta :

Badan Penelitian dan Pengembangan Kesehatan, Departemen Kesehatan Republik Indonesia.

Riset Kesehatan Dasar (2013). Jakarta : Badan Penelitian dan Pengembangan Kesehatan, Kementerian Kesehatan Republik Indonesia.

Riset Kesehatan Dasar (2018). Jakarta : Badan Penelitian dan
Pengembangan Kesehatan, Kementerian Kesehatan Republik Indonesia.

Salim, S. (2017). Gigi Tiruan Jembatan: Fixed Dental Prosthesis. Airlangga University Press.

Silvia, M., \& Suharyono, S. (2014). Karakteristik Pengguna Gigi Tiruan Dengan Pemanfaatan Jasa Tukang Gigi. Journal of Oral Health Care, 1(2), 84-90.

Sinaga, A. A. (2021). Hubungan Tingkat Pengetahuan Masyarakat Pra Lansia Tentang Gigi Tiruan Dengan Minat Pemakaian Gigi Tiruan (Doctoral dissertation, Poltekkes Kemenkes Yogyakarta).

Usri, Kosterman (2007). Tukang Gigi Makin Membahayakan Masyarakat. Dentamedia No 1 Vol 11 Jan-Mar 2007. 